\title{
REVIEW ARTICLE \\ The Effect of Agriculture on Health in Neolithic Populations in the Levant
}

\author{
Fatima Masood* \\ Department of Biochemistry, Microbiology, and Immunology, College of Arts and Science, University of Saskatchewan
}

\begin{abstract}
The purpose of this paper is to analyze the effect that the onset of agriculturalism had on the lives and health of the various Neolithic populations in the Levant during that time. Analysis of bones found at the site of Abu Hureyra (which was occupied by both hunter-gatherers and agriculturalists) show evidence for increased physical stress in the skeletons of agriculturalists, which was due to the physical stress of agriculture (Molleson 1994). Furthermore, musculoskeletal markers on Neolithic male skeletons were shown to be more symmetrical than on Natufian male skeletons. This correlates with the shift from hunting to farming (Eshed et al. 2004). It was also found that the agricultural lifestyle increased the infectious disease rate of farming populations when compared to their Natufian counterparts (Eshed et al. 2010). The shift to an agricultural lifestyle brought about many changes for dental health as well. In Neolithic populations, the rates of dental caries increased, while the wear on their teeth decreased (Eshed, Gopher, and Hershkovitz 2006; Richards 2002). This was due to the increased consumption of carbohydrates and the decreased use of teeth as tools, respectively (Eshed, Gopher, and Hershkovitz 2006; Richards 2002). Furthermore, the mandible was shown to decrease in size in the Neolithic populations when compared to Natufians (Pinhasi, Eshed, and von Cramon-Taubadel 2015). These dental changes were also seen in other areas during the agricultural shift, such as South Asia and South America (Eshed, Gopher, and Hershkovitz 2006).
\end{abstract}

Keywords: agriculture, Neolithic, Natufians, Levant, health profile, paleopathology, skeletal analysis

\section{INTRODUCTION}

The shift from hunting and gathering to agricultural subsistence occurred during the Pre-Pottery Neolithic period (PPN) at approximately 8000-6000 BC (Eshed et al. 2004). In the Levant, a geographical location in the Middle East that includes areas of Lebanon, Jordan, Palestine, Israel, and Syria, the shift to agriculture occurred with changes in settlement patterns, social organization, and ritual practices. Although there is much controversy regarding the nature and sequence of this relation, this paper will instead focus on the health implications of these interrelated changes rather than how they came to be. The presence of the Fertile Crescent, an area of fertile land which spanned from the Persian Gulf to the Mediterranean Sea, was another variable associated with the emergence of agriculture (Eshed et al. 2004). Nearby this

\footnotetext{
* Corresponding author (fam088@mail.usask.ca)
} 
region, along the shoreline of the Mediterranean, was the main area of Natufian occupation prior to the advent of agriculture. The Natufians were a group of hunter-gatherers who lived a semi-sedentary lifestyle wherein they hunted for gazelle and gathered wild cereals (Eshed et al. 2010). During this period many new lifestyle patterns emerged, such as subsistence changes, more sedentary settlement, and social complexity. These interrelated changes in lifestyle, as well as the emergence of agriculture, caused many changes to human health. These changes also characterized the emergence of the Neolithic population. The earliest division of this population, the Pre-Pottery Neolithic, is associated with the earliest evidence of plant domestication (Eshed et al. 2010). When comparing the Natufian and Neolithic cultures that were present in the Levant during the transition to agriculture, many differences can be observed. This paper will discuss the many effects that agricultural subsistence had on the health of the Natufian and Neolithic populations occupying the Levant by comparing health profiles from each population in addition to analyzing Natufian health before and Neolithic health after the introduction of agriculture.

To study the effects that agricultural subsistence had on the populations living in the Levant during this time, one must be able to analyze the skeletal remains of the populations. Estimating the age and sex of skeletal remains are two useful analytical techniques used by archaeologists; however, this is only possible when remains with morphological features that indicate age or sex, such as the pelvic bone or skull, are found. These identifications can be used to group skeletal remains based on shared attributes, such as sex and age. For example, comparing how health profiles differ between adults versus subadults, or between males and females, can reveal intracultural variation between members of the same group or among groups with similar cultural characteristics.
Comparisons can also reveal different physiological markers, which can be used to deduce differences in lifestyle. (Hawkey and Merbs 1995).

The age of skeletal remains can be determined by examining either tooth eruption or bone fusion. Humans are born with two sets of teeth. An individuals age at death can be determined by counting how many sets of teeth are in the skull (Buikstra and Ubelaker 1994). The age of skeletal remains can also be determined using bone fusion. Different bones fuse at different ages; however, one limitation is that once the biological age of 23 is reached, most bones have fused (Buikstra and Ubelaker 1994). Consequently, skeletal remains beyond this age cannot be differentiated from one another. While the bones of a human will completely fuse by the age of 23 , this excludes suture lines on skulls, which begin to fuse at the age of 24 and fuse completely by age 30 to 40 (Meindl and Lovejoy 1985).

The sex of skeletal remains can be determined by comparatively analyzing the pelvic bones. The male pelvis is typically narrower than the female pelvis, with the ilia positioned close together. The female pelvis is wider, with the ilia spread wide apart; the ilia are positioned farther apart in a female to accommodate childbirth. The skull can also be used to identify sex. A male skull has a square jaw and more pronounced brow ridges than a female. In contrast, a female skull instead has a round jaw and chin, as well as a rounded forehead (Buikstra and Ubelaker 1994).

Another research method that is important in analyzing sites in association with agriculture is paleobotany, the study of fossilized plant remains. Paleobotanical evidence can be used to identify the time period in which the intensification of cultivation of domestic cereals or legumes occurred. According to paleobotanical evidence, agriculture occurred in the Levant at the beginning of the Holocene (approximately 11,500 years ago). Using paleobotany, it was discovered that Natufian 
populations mainly processed wild cereals, whereas the Neolithic populations were found to shift from wild cereal processing to the domestication of cereals and legumes while continuing to rely on wild seeds, fruits, and hunting. This data can be used to contextualize the daily life and diet of the individuals that lived in this area. Reconstructing diet can help to explain the wear on teeth and to understand the many physical stress markers and pathologies present in these populations (Pinhasi, Eshed, and von Cramon-Taubadel 2015).

\section{MARKERS OF PHYSICAL STRESS}

One of the changes that occurred with the shift to agriculturalism was the onset of physical stress, which can be determined by studying any signs of osteoarthritis on skeletal remains as well as any muscle markings that may indicate physical stress (Eshed et al. 2010). Numerous studies have shown that the transition to an agricultural lifestyle leads to increased physical stress levels. In a study conducted by Molleson (1994), 162 skeletons found at the site of Abu Hureyra were examined and used to reconstruct the daily lives of the people who had lived there. The data collected at Abu Hureyra were extremely important, as this site was occupied two different times. The first inhabitants of this site were a pre-Neolithic group who lived there approximately 11,500-10,000 years ago. The second inhabitants of this site appeared approximately 200 years later. The latter group represented a Neolithic farming community. These two populations were compared using their skeletal remains, which provided a comparison between pre-Neolithic and Neolithic society (Molleson 1994).

One of the first signs of stress found on the Neolithic bones were changes in the upper vertebrae of the adolescents. This stress was most likely due to carrying heavy loads, such as game, grain, and building materials. This change in the upper vertebrae was mainly found in the bones of adolescents, which indicated that adolescents were heavily involved withagricultural labour The preparation of grains was a physically demanding activity which caused many deformities in the neck vertebrae. This degeneration of the neck vertebrae may have been caused by kneeling to grind grains by hand using saddle querns (grinding tools made of stone), which were found during excavations conducted by Molleson (1994). However, these deformities may also have developed due to the constant pounding of seeds using a pestle and mortar while kneeling. Furthermore, the act of grinding puts pressure on the hips and lower back in addition to the pressure on the toes and knees during kneeling. This additional pressure can cause damages to the vertebrae, most commonly disc damage and crushing. The bones found at Abu Hureyra exhibitied indications of physical stress. For example, a spine belonging to a Neolithic Abu Hureyra female showed multiple bony growths along the vertebrae. These growths are believed to have occurred due to the hours spent bent over, kneeling, and grinding grains. A typical female in this area would have kneeled while using a mortar and pestle for grinding grains. This position would have placed strain on the knees, toes, lower back, and arms. These areas of the skeleton would contain physical markers of this excessive strain placed on them, and therefore can be used to identify communities that were processing grains this way (Molleson 1994).

In another study conducted by Eshed et al. (2004), Natufian and Neolithic populations in the Levant were compared by looking at musculoskeletal markers (MSM) in the upper limbs. When comparing males and females within the Natufian populations, it was discovered that females tended to have a higher level of bilateral symmetry in MSM compared to males; males tended to be more asymmetric. This asymmetry may have been caused by 
hunting, which put greater stress on the dominant throwing hand of a male. Neolithic males and females were also compared; however, the data showed that there were more similarities in MSM between these groups. The findings showed a greater similarity between male and females, as well as decreasing asymmetrical lateralization in males. The increasing similarity of male and female MSM was likely due to the intensification of activities, such as hunting, gathering, and producing stone tools as well as the introduction of new activities, such as mud-brick construction (Eshed et al. 2004).
Another difference discovered when comparing the MSM of Neolithic males and females was that females tended to have higher MSM scores than males in muscles around the elbow, as well as muscles attached to the forearm. These muscles are mainly involved in finer hand movements. This indicates that there were specific types of labours allotted for males and females. Females were most likely responsible for activities that required focused dexterity, such as basketry. The results of this study showed that labour increased in both sexes with the onset of agriculture; however,

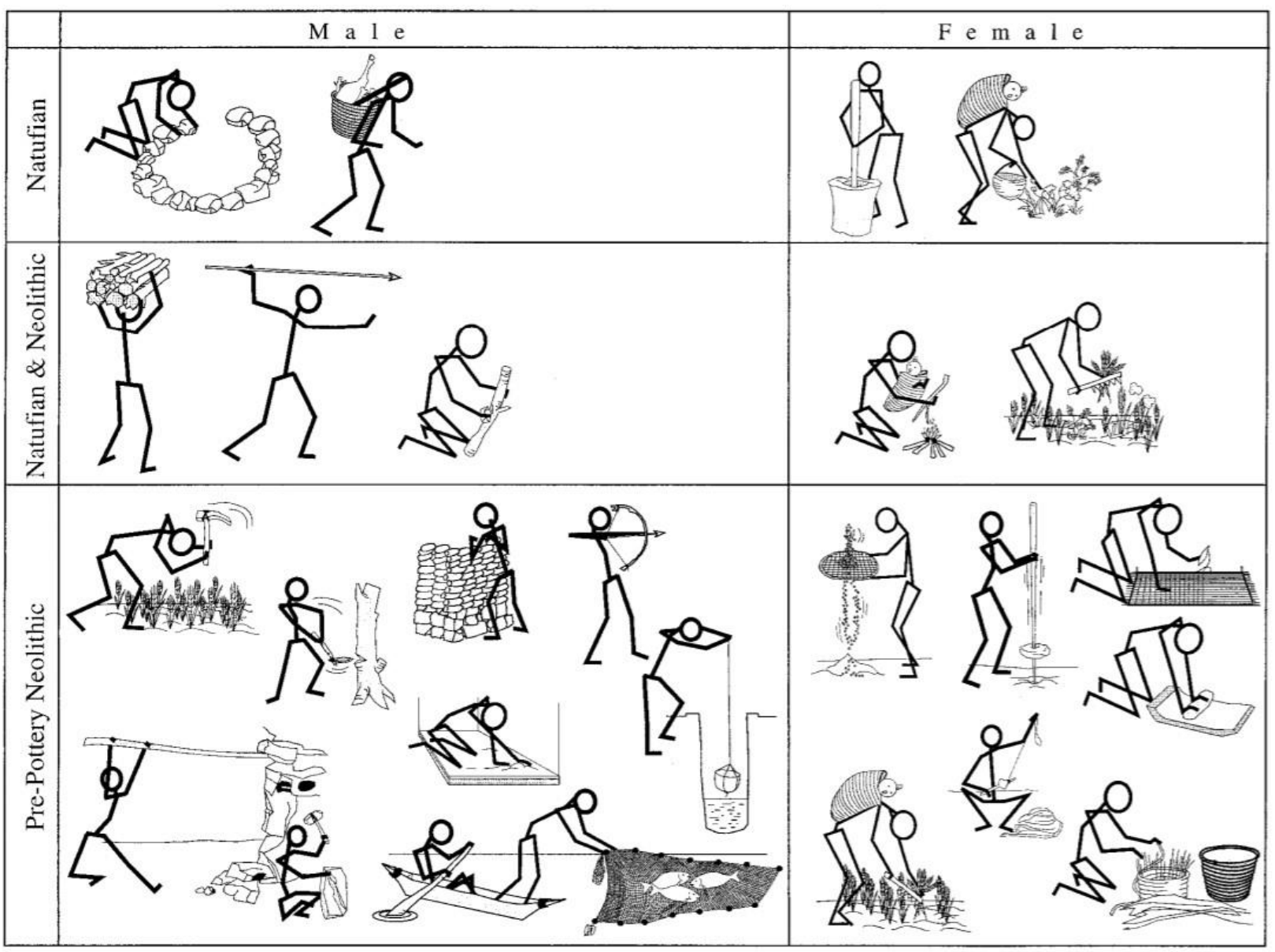

FIGURE 1- Image displaying the major activities for Natufian and Neolithic males and females. Note: This chart displays the different activities that were performed by males and females in Natufian and Neolithic populations. As shown, there is an increase in activities for Pre-Pottery Neolithic populations which is related to the increase in MSM in skeletal remains. The increase in both male and female workload also explains the increased similarity in MSM in male and female skeletons (Eshed et al. 2004). Reproduced with permission from the American Journal of Physical Anthropology, John Wiley \& Sons. 


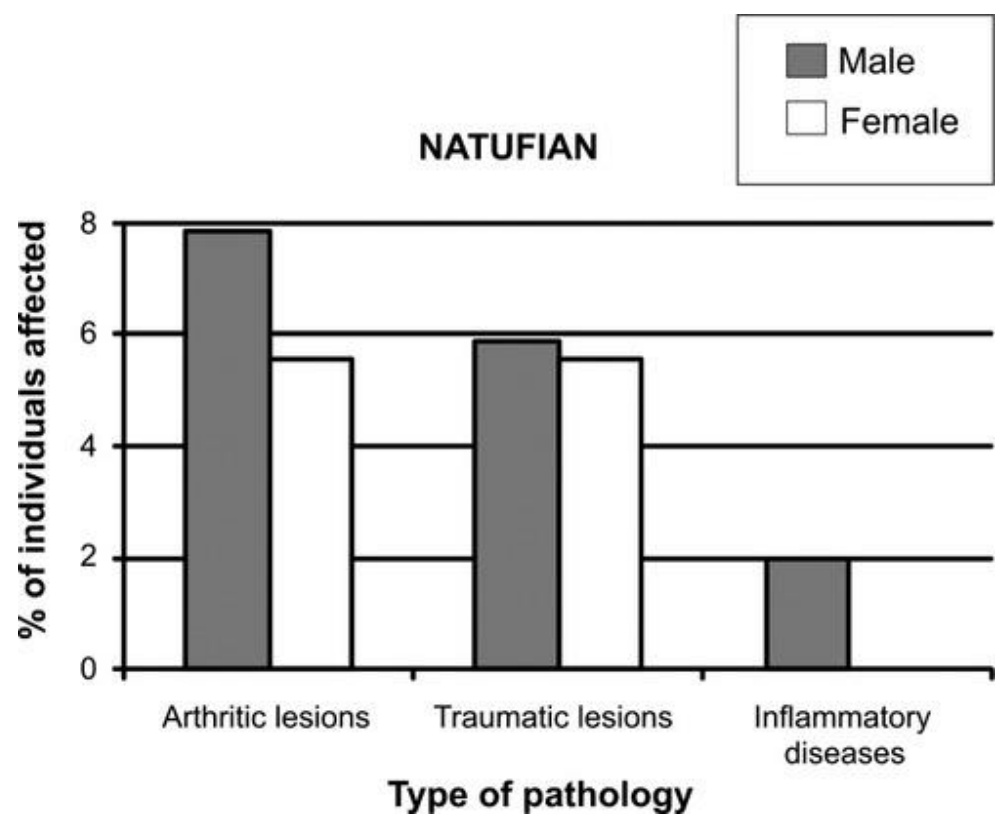

FIGURE 2- Natufian pathology bar graph. Note: Bar chart displaying the occurrence of three different pathologies (arthritic lesions, traumatic lesions, and inflammatory diseases) amongst Natufian male and female skeletal remains. In all three categories, male Natufians scored higher than the females. It also shows that no Natufian female showed any evidence for inflammatory disease (Eshed et al. 2010). Reproduced with permission from the American Journal of Physical Anthropology, John Wiley \& Sons.

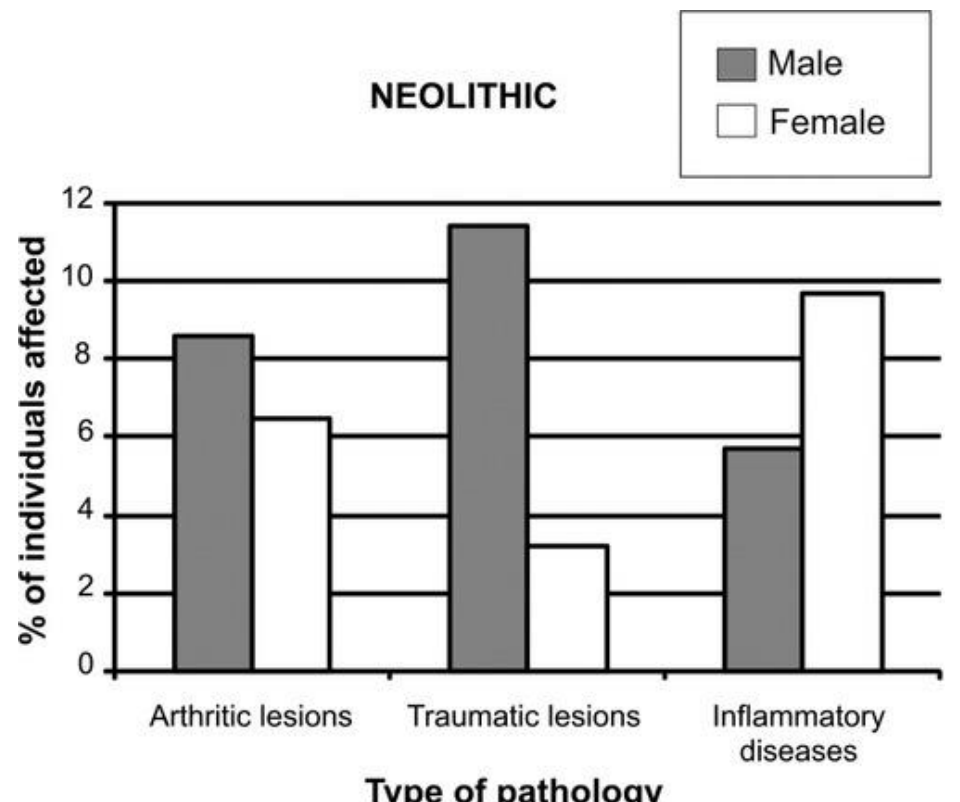

FIGURE 3- Neolithic pathology bar graph. Note: Bar chart displaying the occurrence of three different pathologies (as in Figure 2) amongst Neolithic male and female skeletal remains. The most important difference shown is the increase in inflammatory disease for both male and females. Furthermore, it shows that females showed a higher increase in inflammatory diseases than males (Eshed et al. 2010). Reproduced with permission from the American Journal of Physical Anthropology, John Wiley and Sons Inc. 
females were more involved with subsistence activities than males, which was proven by the increasing MSM scores found in Neolithic females (Eshed et al. 2004).

As shown by Figures 2 and 3, arthritic lesions increased in Neolithic populations compared to the Natufians. Furthermore, there was little difference in the rate of arthritic lesions between sexes. This trend was also reported at Dickson Mound, United States, as well as at pre- and post-agricultural sites in Portugal (Bridges 1991). These trends reveal a positive association between increased physical stress and the onset of agriculture. In the Levant, arthritic lesions were shown to be more prevalent in the male Neolithic population than the female population (Eshed et al. 2010). These arthritic lesions reflect the intensification in physical activities and may indicate sex-specific occupations that occurred during the transition to agriculture (Eshed et al. 2004).

A study conducted on hunter-gatherer and farming populations who occupied Northwestern Alabama during the transition to agriculture revealed more information on how degenerative joint diseases affected these populations, and how these changes were related to the transition to agriculture (Bridges 1991). In these populations, it was proven that there were very few differences between male and female hunter-gatherers. In contrast, it was shown that male skeletal remains from farming societies displayed a significantly higher level of osteoarthritis than females. This difference indicates sex-specific activities in this society. It is believed that the osteoarthritis was a response to the increased workload, which increased the physical stress placed on the body (Bridges 1991).

Physical stress markers on skeletal remains can indicate how different stresses on the body affect bones. Subsequently, studying bones and stress markers from the time period of agricultural intensification can reveal the effects that agriculture had on the human body.
Based on the aforementioned analyses, there is a clear association between the transition to agriculture and the physical stress placed on the body; this association has been reported in multiple early farming communities (Bridges 1991).

\section{INFECTIOUS DISEASE}

The onset of agriculture also led to the emergence of civilization pathogens (Eshed et al. 2010). Civilization pathogens are pathogens that require an increased population in order to persist in the environment (Pearce-Duvet 2006). It is estimated that these pathogens would not exist without the development of agriculture. This is because prior to agriculture, populations were not dense enough to allow for these pathogens to persist, as transmission from person-to-person is vital for their survival. These pathogens were likely extracted from domesticated animals, such as sheep and goats. During the early stages of agriculture, livestock was kept close to living areas. This close proximity facilitated the transmission of pathogenic bacteria from livestock to humans (Eshed et al. 2010). The analyses of Neolithic skeletal remains from the Levant have revealed evidence of systemic infections, which confirmed the presence of infectious diseases such as tuberculosis and syphilis within these agricultural populations (Eshed et al. 2010).

Infections can cause lesions to form on skeletons, which is how archaeologists are able to diagnose infectious diseases, such as tuberculosis (Hershkovitz et al. 2008); however, it is important to mention the osteological paradox. This concept addresses the obfuscating nature of osteological pathologies wherein individuals who die shortly after developing an infection may not show any signs of infection on their skeleton, while individuals who live with infection may develop lesions on their skeleton. Due to this paradox, the existence of 
a disease may be misinterpreted; thus, interpretations of skeletal lesions must be carefully considered (Siek 2013; Wood et al. 1992).

Tuberculosis can cause changes in the skeleton, such as the collapse of the vertebrae, osteomyelitis (the infection of bone), and periosteal reactive lesions (the formation of bone due to injury) (Hershkovitz et al. 2008). These skeletal changes have been reported in many areas, including predynastic Egypt (3500$2650 \mathrm{BC}$ ), and are associated with early agriculturalists (Hershkovitz et al. 2008). Using skeletal evidence, it was determined that tuberculosis was a predominant disease in the Neolithic populations in the Levant (Eshed et al. 2010). These lesions may have occurred due to changes in lifestyle and subsistence, including sedentism, the increase of population density, the introduction of facilities used for storage, animal domestication, and farming. It is likely that storage facilities, which led to the introduction of commensal species such as mice, coupled with animal domestication and sedentism enabled pathogenic strains to jump from animals to humans, subsequently increasing the rate of infectious disease among agricultural populations in the Levant (Eshed et al. 2010).

In Eshed's (2010) study on the health profiles of Neolithic and Natufian skeletal remains, it was concluded that there was a significant increase in infectious disease occurring in Neolithic populations compared to the Natufian populations. While it is not possible to obtain direct evidence for infection resistance, inferences can be made based on data. If resistance had not formed, there would be an increased mortality rate as well as a decreased life expectancy age; however, that is not what the researchers found. In a study conducted by Eshed et al. (2003), skeletal analysis and the construction of a life table (a technique measure mortality) showed that the life expectancy age at birth and the mean age at death for adults increased for the Neolithic population (Eshed et al. 2003). This data proved a lower rate of mortality and an increased life expectancy for this group (Eshed et al. 2003). Furthermore, there was an apparent rise in improvement for health in the Neolithic population, which was expected with increased resistance against several infectious diseases (Eshed et al. 2010). In a study conducted by Smith and Kolska-Horwitz (2007), the health profiles of Middle PrePottery Neolithic B (MPPNB) villages and late to final Natufian Pre-Pottery Neolithic A (PPNA) villages were determined through multiple analytical techniques. The MPPNB period is associated with early agricultural villages, while the late to final PPNA period is associated with the final Natufian period. Smith and Kolska-Horwitz (2007) concluded that the health of the MPPNB populations were significantly better than populations from the previous PPNA period by identifying periods of high and low health. The periods of low health were associated with environmental deterioration and settlement pattern changes, while the period of high health was associated with an agricultural lifestyle. The results of both studies support the idea that an improvement in health (which involves a decreased mortality rate and increased life expectancy age) would be associated with an increase in resistance against several infectious diseases (Eshed et al. 2003, 2010; Smith and KolskaHorowitz 2007)

Studying skeletal remains found in the Levant indicates that the rate of infection among occupying populations increased with the transition into agriculture. Studies involving early agricultural societies worldwide have also shown that the emergence of agriculture is associated with the emergence of infectious disease such as smallpox, measles, malaria, schistosomiasis, and tuberculosis (Hershkovitz et al. 2008). Additional studies could be used to understand if there were any sex-specific differences in the rates of infectious diseases that could further contribute to understanding 
differences in sex-specific activities. Furthermore, research conducted on ancient infectious diseases can also aid in the understanding of the evolution of these diseases and how they evolve to affect humans differently.

\section{DENTAL HEALTH}

The transition to agriculture is also associated with many distinctive changes in dental health between the Natufian and Neolithic populations that occupied the Levant. In a study comparing these populations, many differences in oral health were noticed (Richards 2002). The Natufian population were found to have fairly healthy teeth with very little evidence for caries (the decay and crumbling of a tooth). In contrast, in the Neolithic populations, teeth were found to have increased rates of caries. The increased rates of caries are believed to be due to the diet change associated with agriculture. The Neolithic populations in the ancient Near East are believed to have an increased diet of plant foods containing carbohydrates, which increased their rates of caries (Richards 2002).

When compared to the Natufian population, the Neolithic dental remains were found to have less dental wear on them. This also follows the trend displayed by the transition to agriculture found in other parts of the world (Eshed, Gopher, and Hershkovitz 2006). For example, in a study conducted by Molnar (1971), the differences in tooth wear between non-agricultural and agricultural Native Americans from California, the Southwest, and the Valley of Mexico showed the same differences found between Natufian and Neolithic populations. This shows a strengthened association between the emergence of agriculture and a lower rate of tooth wear. This lower rate of tooth wear for Neolithic agricultural groups may be due to the decrease in strenuous mastication (Eshed, Gopher, and Hershkovitz 2006). This decrease may have been due to the declining use of a stone mortar and pestle to pound food items, which would introduce tiny stone pieces into their diet that required intensified chewing (Eshed, Gopher, and Hershkovitz 2006). Instead, Neolithic populations increasingly ground their food items. Furthermore, the wear on Natufian teeth can also be explained by the usage of their teeth as tools. For example, the Natufian population found at Ain Mahalla contained wear grooves on their teeth from using their teeth as tools, which is shown in Figure 4.

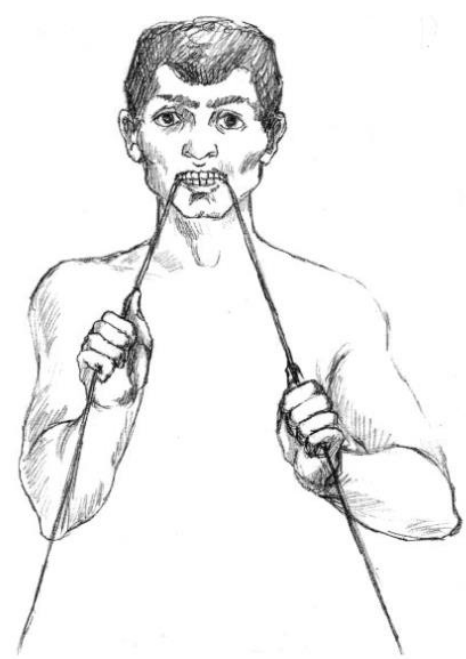

FIGURE 4-Drawing of a Natufian. Note: A drawing of how Natufians may have used their teeth as tools. The person in the drawing is shown to be holding staves in their teeth. This material could be used to make either baskets or fishing nets (Eshed, Gopher, and Hershkovitz, 2006). Reproduced with permission from the American Journal of Physical Anthropology, John Wiley \& Sons. 
Another explanation can be derived from the Natufian usage of mortars and pestles used for pounding nuts and seeds. The nuts and seeds processed this way were coarse, which would have caused dental wear on the teeth (Eshed, Gopher, and Hershkovitz 2006).

Dental attrition, a type of tooth wear caused by tooth-to-tooth contact, is also prevalent in pre-agricultural societies. Dental attrition rates are affected by the type of food eaten, the consistency or texture of the food, as well as how the food was prepared. The shift to agriculture brought many changes in all three categories, which are associated with a decrease in dental attrition rates in agricultural societies. This decrease is also attributed to the decrease in the roughness of agricultural foods due to the declining use of a stone mortar and pestle for food processing. Instead, grinding had become more prevalent (Eshed, Gopher, and Hershkovitz 2006).

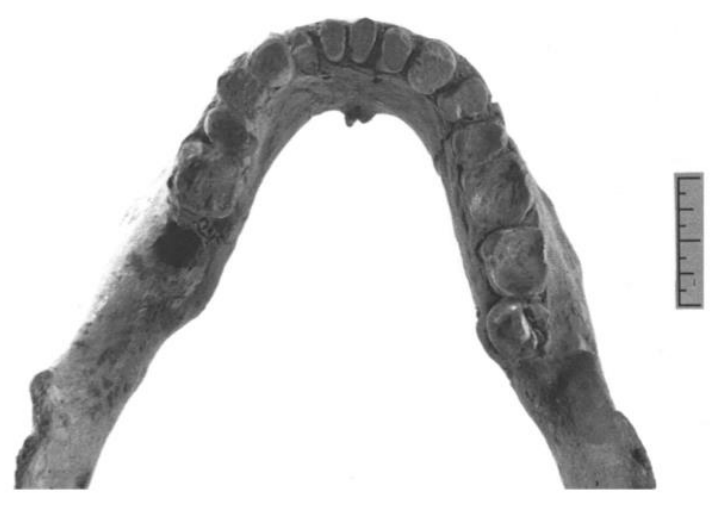

FIGURE 5-Photo of Natufian dental attrition. Note: A photo displaying the dental attrition that is typical of the Natufian populations. Note that the tops of the teeth are flattened. Natufian populations typically have a pattern of wear that shows an even flatness across all teeth (Eshed, Gopher, and Hershkovitz 2006). Reproduced with permission from the American Journal of Physical Anthropology, John Wiley \& Sons.

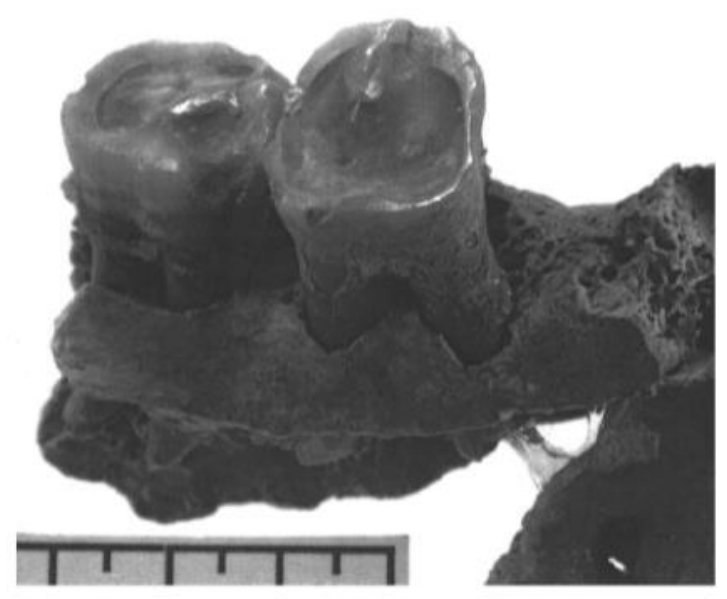

FIGURE 6- Photo of Neolithic dental attrition. Note: A photo displaying the dental attrition that occurred in Neolithic populations. In Neolithic populations, the attrition is more angular than flat and was not evenly distributed (Eshed, Gopher, and Hershkovitz 2006). Reproduced with permission from the American Journal of Physical Anthropology, John Wiley \& Sons. 
Declining dental health in response to the beginnings of agriculture occurred in other parts of the world as well. The domestication of rice in South Asia as well as the domestication of maize in South America caused increased rates of caries in the agricultural populations that were present in these areas during the transition to agriculture. The rates of caries also increased in European populations; however, in some populations, the changes were not present until the Bronze Age (3000-1200 BC). Direct stable isotope analysis was used to track the cultivation of maize in South America, which corresponded with the increased caries shown in the teeth of agriculturalists in South America. In many areas, there was shown to be a general decrease among dentition size as well. This decrease in size is most likely due to agriculturalists switching their diets to easier-to-chew foods, such as bread and porridges, which required less robust dentition (Eshed, Gopher, and Hershkovitz 2006).

In a study conducted on the Abu Hureyra populations, Molleson (1994) identified a subset of the population that was involved in fibre production. This population was identified to be mainly female. This population of fibre specialists was identified by distinctive grooves found on their teeth and by wear on the teeth evidenced by larger mandibular joint surfaces. Similar dental characteristics were shown in ethnographic study populations who used their mouths as clamps and tools in fibre processing. Comparisons between the two populations allowed archaeologists to conclude that the skeletal remains that had these certain characteristics partook in similar activities. This example demonstrates that by analyzing dental remains, sex differentiation between activities can be recognized (Molleson 1994).

The transition to agriculture is associated with a significant reduction in size of the mandible. However, this change cannot be attributed to low dental wear, as that would cause hunter-gatherers to have a reduced mandible size as well, which is not the case for hunter-gatherer groups (Pinhasi, Eshed, and von Cramon-Taubadel 2015). There are many key differences between hunter-gatherer and agriculturalist dentition features. Hunter-gatherer populations usually have a larger crown size, as well as occlusal and interproximal tooth wear. Malocclusion (the misalignment of the teeth) dental crowding, and oral disease are nearly non-existent in hunter-gatherer populations. Hunter-gatherer populations also show a positive association between mandibular shape and dental shape, while this association was not found in agriculturalists. This lack of association in agriculturalists may be attributed to the shift towards agriculturalism and sedentism, as agriculture included a more consistent diet. In addition to the changes in lifestyle and diet, mandibular plasticity caused a reduction in dentition size amongst agriculturalists (Pinhasi, Eshed, and von Cramon-Taubadel 2015).

The adoption of agriculture initiated major changes in the human diet. These changes are associated with the agriculturalist populations in the Levant that underwent major changes in dentition. The rate of caries increased with agriculture, while tooth wear decreased. The size of the mandible and dental attrition decreased as well. Furthermore, using data from tooth analyses, archaeologists were able to reconstruct lifestyle and diet. Using ethnographic data and dental analysis, it is possible to contextualize the lives of the populations present in the Levant during the transition to agriculture. This context can be used to deduce what life was like during the Agricultural Revolution.

\section{CONCLUSION}

The purpose of this paper was to examine the differences between the Natufian popula- 
tion that existed before the advent of agriculture in the Levant and the Neolithic population that existed afterwards in order to understand the impacts of agriculture on physical health. Analysis of skeletal remains through the study of paleopathology is important in this examination, as it allows for many aspects of ancient civilization to be understood such as daily life and health. The transition to an agricultural lifestyle brought many new changes to the lifestyles of the Natufians, which caused major changes in their diet and health. Many of these changes had a negative impact on humans, as it brought an increased rate of physical stress and infectious disease; however, some impacts were positive, such as the decreased amount of tooth wear. The new diet that Neolithic populations consumed was less coarse than it had been among pre-agricultural Natufians, resulting in lower instances of tooth wear among Neolithic skeletal remains. Through research on skeletal remains, the change brought on by agriculture can be further studied in order to give more context to what life was like for Levant populations during the transition to agriculture. By looking at skeletal markers, different activities can be determined, which can be used to reconstruct ancient life. This is important as it expands the current knowledge that is available on how people in the Levant lived prior to an agricultural lifestyle as well as how they lived afterward. With further research about pre- and post-agricultural societies across the world, it can be determined why an agricultural society paved the way for civilizations to form as well as why this subsistence pattern has remained dominant among human populations.

\section{REFERENCES}

Bridges, Patricia S. 1991. "Degenerative Joint Disease in Hunter-Gatherers and Agriculturalists from the Southeastern United States." American Journal of Physical Anthropology 85, no. 4 (August): 379-391. https://doi.org/10.1002/ajpa.1330850403
Buikstra, Jane E. and Douglas H. Ubelaker, eds. 1994. Standards for Data Collection from Human Skeletal Remains: Proceedings of a Seminar at the Field Museum of Natural History. Arkansas Archeological Survey Research Series, 44. Fayetteville AR: Arkansas Archeological Survey.

Eshed, Vered. Avi Gopher, Timothy B. Gage, and Israel Hershkovitz. 2003. "Has the Transition to Agriculture Reshaped the Demographic Structure of Prehistoric Populations? New Evidence from the Levant." American Journal of Physical Anthropology 124, no. 4 (November): 315-329. https://doi.org/10.1002/ajpa. 10332

Eshed, Vered, Avi Gopher, Ehud Galili, and Israel Hershkovitz. 2004. "Musculoskeletal Stress Markers in Natufian HunterGatherers and Neolithic Farmers in the Levant: The Upper Limb." American Journal of Physical Anthropology 123, no. 4 (April): 303-315. https://doi.org/10. 1002/ajpa.10312

Eshed, Vered, Avi Gopher, Ron Pinhasi, and Israel Hershkovitz. 2010. "Paleopathology and the Origin of Agriculture in the Levant." American Journal of Physical Anthropology 143, no. 1 (September): 121-133. https://doi.org/10.1002/ajpa.213 01

Eshed, Vered, Avi Gopher, and Israel Hershkovitz. 2006. "Tooth Wear and Dental Pathology at the Advent of Agriculture: New Evidence from the Levant." American Journal of Physical Anthropology 130, no. 2 (June): 145-159. https://doi.org/10.1002/ajpa.20362 
Hawkey, Diane E. and Charles F. Merbs. 1995. "Activity-Induced Musculoskeletal Markers (MSM) and Subsistence Strategy Changes among Ancient Hudson Bay Eskimos. International Journal of Osteoarchaeology 5, no. 4: 324-338. https://doi.org/10.1002/oa.1390050403

Hershkovitz, Israel, Helen D. Donoghue, David E. Minnikin, Gurdyal S. Besra, Oona Y-C. Lee, Angela M. Gernaey, Ehud Galili et al. 2008. "Detection and Molecular Characterization of 9000-YearOld Mycobacterium tuberculosis from a Neolithic Settlement in the Eastern Mediterranean." PLOS One 3, no.10: e3426. https://doi.org/10.1371/journal.pone. 0003426

Meindl, Richard S. and C. Owen Lovejoy. 1985. "Ectocranial Suture Closure: A Revised Method for the Determination of Skeletal Age at Death Based on the Lateral-Anterior Sutures. American Journal of Physical Anthropology 68, no. 1: 57-66. https://doi.org/10.1002/ajpa.13306 80106

Molleson, Theya. 1994. "The Eloquent Bones of Abu Hureyra." Scientific American 271, no. 2: 70-75. https://doi.org/10.1038/ scientificamerican0894-70

Molnar, Stephen. 1971. "Human Tooth Wear, Tooth Function and Cultural Variability." American Journal of Physical Anthropology 34, no. 2 (March): 175-189. https://doi.org/10.1002/ajpa.1330340204

Pearce-Duvet, Jessica M. C. 2006. "The Origin of Human Pathogens: Evaluating the Role of Agriculture and Domestic Animals in the Evolution of Human Disease." Biological Reviews 81, no. 3: 369-382. https://doi.org/10.1017/S1464793106007 020
Pinhasi, Ron, Vered Eshed, and Noreen von Cramon-Taubadel. 2015. "Incongruity between Affinity Patterns Based on Mandibular and Lower Dental Dimensions Following the Transition to Agriculture in the Near East, Anatolia and Europe." PLOS One 10, no. 2 (April): e0117301. https://doi.org/10.1371/journal.pone. 0117301 .

Richards, Michael P. 2002. "A Brief Review of the Archaeological Evidence for Palaeolithic and Neolithic Subsistence." European Journal of Clinical Nutrition 56, no. 12 (December): 12701278. https://doi.org/10.1038/sj.ejcn.160 1646.

Siek, Thomas. 2013. "The Osteological Paradox and Issues of Interpretation in Paleopathology." vis-à-vis: Explorations in Anthropology 13, no. 1, 92-101.

Smith, Patricia and Liora Kolska-Horwitz. 2007. "Ancestors and Inheritors: A Bioarchaeological Perspective on the Transition to Agropastoralism in the Southern Levant." In Ancient Health: Skeletal Indicators of Agricultural and Economic Intensification, edited by Mark N. Cohen and Gilliam M. M. Crane-Kramer, 207222. Gainesville: University Press of Florida.

Wood, W. James, George R. Milner, Henry C. Harpending, Kenneth M. Weiss, Mark N. Cohen, Leslie E. Eisenberg, Dale L. Hutchison et al. 1992. "The Osteological Paradox: Problems of Inferring Prehistoric Health from Skeletal Samples." Current Anthropology 33, no. 4 (August): 342-270. https://doi.org/10.1086/204084 